\title{
Renewable Energy and Carbon Management in the Cradle-to-Cradle Certification Limitations and Opportunities
}

\author{
Niero, Monia; Olsen, Stig Irving; Laurent, Alexis
}

Published in:

Journal of Industrial Ecology

Link to article, DOI:

$10.1111 /$ jiec. 12594

Publication date:

2018

Document Version

Peer reviewed version

Link back to DTU Orbit

Citation (APA):

Niero, M., Olsen, S. I., \& Laurent, A. (2018). Renewable Energy and Carbon Management in the Cradle-toCradle Certification: Limitations and Opportunities. Journal of Industrial Ecology, 22(4), 760-772.

https://doi.org/10.1111/jiec.12594

\section{General rights}

Copyright and moral rights for the publications made accessible in the public portal are retained by the authors and/or other copyright owners and it is a condition of accessing publications that users recognise and abide by the legal requirements associated with these rights.

- Users may download and print one copy of any publication from the public portal for the purpose of private study or research.

- You may not further distribute the material or use it for any profit-making activity or commercial gain

- You may freely distribute the URL identifying the publication in the public portal

If you believe that this document breaches copyright please contact us providing details, and we will remove access to the work immediately and investigate your claim. 
$1 \quad$ Journal of Industrial Ecology

2 Type of contribution: Research and analysis

3

4 Renewable energy and carbon management in the Cradle-to-Cradle

5 certification: Limitations and opportunities

6 Monia Niero $^{1 *}$, Stig I. Olsen ${ }^{1}$, Alexis Laurent ${ }^{1}$

7

$8{ }^{1}$ Division for Quantitative Sustainability Assessment, Department of Management Engineering,

9 Technical University of Denmark, Bygningstorvet, Building 115, 2800 Kgs. Lyngby, Denmark

* To whom correspondence should be addressed: email: monni@dtu.dk ; Tel.: +45 45251640 


\section{Summary}

As part of the Cradle to Cradle ${ }^{\circledR}(\mathrm{C} 2 \mathrm{C})$ certification program, the $\mathrm{C} 2 \mathrm{C}$ certification criterion “Renewable Energy and Carbon Management" (RE\&CM) focuses on use of electricity from RE and direct greenhouse gas offsets in the manufacturing stage and to a limited extent on the cradle to gate only at the highest level of certification. The aim of this study is to provide decision-makers with a quantified overview of possible limitations of that $\mathrm{C} 2 \mathrm{C}$ certification requirement and potential gains by introducing a full Life Cycle Assessment (LCA) perspective to the scheme. Scenario analysis was used to perform an LCA of an aluminum can system representing different levels of the $\mathrm{C} 2 \mathrm{C}$ certification criterion RE\&CM, considering different strategies to achieve $100 \%$ $\mathrm{RE}$ in the manufacturing stage. The adoption of a broader life cycle RE perspective was considered through the implementation of electricity from renewable sources from cradle to grave. Our results show that compliance with the current RE\&CM certification framework offers limited benefits, i.e. significant reduction for climate change but negligible reductions for other environmental impacts, e.g. particulate matter and acidification. However, increasing the share of RE in the primary aluminum production from a full life cycle perspective can greatly increase the environmental benefits brought up by the $\mathrm{C} 2 \mathrm{C}$ certification, not only for climate change, but for the broader range of impact categories. In our striving towards environmental sustainability, which often cannot be approximated by climate change impacts alone, we therefore recommend decision-makers in industries to combine the $\mathrm{C} 2 \mathrm{C}$ certification with LCA when they define strategies for the selection of renewable energy and raw materials suppliers.

Keywords (max 6): Life Cycle Assessment (LCA), aluminum, packaging, circular economy, C2C, decision support 


\section{<heading level 1> Introduction}

With the current political and business emphasis on circular economy, defined as a restorative or regenerative industrial system by intention and design (EMF 2013; EC 2015), the Cradle-to-Cradle ${ }^{\circledR}$ (C2C) design framework has gained an increasing visibility in industry (Toxopeus et al. 2015). C2C is a design framework oriented towards product quality and innovation, aiming to maximize the overall benefits of products to ecological and economical systems by designing "eco-effective" solutions. C2C relies on three key principles: "waste equal food”, "use current solar income” and “celebrate diversity”(McDonough and Braungart 2002). Until now in the circular economy context, efforts have largely focused on implementing the former, i.e. attempting to shift from a waste paradigm to a resource one, where waste from some industries can serve as resources for others. To allow companies to monitor and market their progress in $\mathrm{C} 2 \mathrm{C}$ compliance, a certification program known as the Cradle to Cradle Certified ${ }^{\mathrm{TM}}$ Product Standard was established and recently updated (Cradle to Cradle Products Innovation Institute 2016). Applicants have to comply with a series of requirements for five categories: material health $(\mathrm{MH})$, material reutilization $(\mathrm{MR})$, renewable energy and carbon management (RE\&CM), water stewardship (WS) and social fairness (SF), each of them being scored on a 5-grade scaling system, i.e. basic, bronze, silver, gold and platinum, reflecting an increased stringency in the $\mathrm{C} 2 \mathrm{C}$ requirements.

As already discussed in past studies (Bjørn and Hauschild 2013; Toxopeus et al. 2015), the trade-off between resource conservation and energy use is a weakness of the $\mathrm{C} 2 \mathrm{C}$ design framework and therefore of the certification program. For all the grades but platinum in the scaling system, only electricity use and greenhouse gases (GHGs) emissions in the manufacturing stage of a product are thus considered. This means that for most of the grades the environmental impacts stemming from the raw materials extraction, production, construction, and decommissioning of the energy generation facilities are disregarded even though those stages may be important drivers of the environmental impacts. This is particularly relevant for energy production based on renewable 
energy sources e.g. wind (Dolan and Heath 2012; Turconi et al. 2013; Asdrubali et al. 2015) or solar power (Hsu et al. 2012; Turconi et al. 2013; Asdrubali et al. 2015), for which life cycle assessment (LCA) showed relatively low environmental impacts in the use/operation stage compared to their production and disposal stages. Moreover, the need to include a broader range of impact categories than climate change to gauge the environmental sustainability when shifting electricity production from the use of fossils to the use of renewables has been pointed out (Laurent et al. 2012; Hertwich et al. 2014).

These gaps in the $\mathrm{RE} \& \mathrm{CM}$ requirement of the $\mathrm{C} 2 \mathrm{C}$ certification can induce important biases in the decision making process for companies, who might not be aware of such limitations and associated uncertainties. In this study, we therefore aim to provide decision-makers in industry a quantified overview of possible limitations of the RE\&CM requirement and potential gains by introducing a full LCA perspective, as well as recommendations to alleviate these shortcomings in decisionmaking processes.

We build on the results of an existing LCA of aluminum beverage cans (termed "AlC system" in the following) (Niero et al. 2016). We focus on (primary) aluminum production, which belongs to those sectors, where energy consumption during manufacturing is an environmental hotspot of the technologies and systems (EAA 2013) and is thus fully relevant from a life cycle perspective (Liu and Müller 2012). Due to its rapid aluminum industry development in the last decade, China has become the largest primary aluminum producer in the world and now faces urgent needs to reduce associated environmental impacts (Sun et al. 2015). As a result, the longtime front-runner in aluminum production, Europe, is today the second largest producer (http://www.worldaluminium.org/statistics/). Chinese and European aluminum productions differ from each other with regard to their supporting electricity mixes, which are mainly based on coal and hydropower, respectively. In the current study, we therefore consider different can systems including either China or Europe as aluminum-producing countries: (1) the AlC system as commonly in place (baseline scenario), (2) the $\mathrm{AlC}$ system with implementation of the $\mathrm{C} 2 \mathrm{C}$ certification requirement at 
the highest grades for the RE criterion (i.e. gold and platinum) using alternative renewable energy sources, and (3) the AlC system with adoption of a broader life cycle RE perspective, i.e. implementation of electricity from renewable sources from cradle to grave.

\section{<heading level 1> Materials and methods}

Aluminum cans systems have recently been evaluated by means of LCA, e.g. van der Harst and colleagues (2015). We consider here an AlC system for beer containment in the UK market previously used to model 20 different scenarios complying to different degrees with two of the C2C certification requirements, namely RE and MR (Niero et al. 2016). We followed the requirements of the ISO 14040-44 standards (ISO 2006a, 2006b) and the technical guidance provided by International Reference Life Cycle Data System (ILCD) handbook (EC-JRC-IES 2010). We also used the approach from the product environmental footprint (PEF) guide (EC 2013) to model the end-of-life (EoL) as it is the one recommended in the context of policy support applications (Allacker et al. 2014).

\section{<heading level 2> Goal and scope of the LCA}

The goal of the LCA study is to compare different AlC systems, some representative of different level of compliance with the requirements of the $\mathrm{C} 2 \mathrm{C}$ certification for the $\mathrm{RE} \& \mathrm{CM}$ criterion, and some going beyond $\mathrm{C} 2 \mathrm{C}$ certification through the inclusion of $\mathrm{RE}$ in a life cycle perspective, considering the average primary aluminum production in either Europe or China. Since the aim of the LCA is to provide decision support related to product development, with small scale changes in the background system, i.e. in terms of energy supply and material supplier, then the decision context is a situation A type according to the ILCD Handbook, i.e. micro-level decision support (EC-JRC-IES 2010). The considered functional unit is "the containment of 1 hl of beer until the 
109 expiry date", in accordance with the draft version of the PEF category rules for beer published in 110 the context of the beer PEF pilot (Technical Secretariat for the Beer Pilot 2015). In the case of $33 \mathrm{cl}$ 111 aluminum cans, with average weight of $13.5 \mathrm{~g}, 4.22 \mathrm{~kg}$ of material per functional unit is required 112 (Niero et al. 2016). Only the primary packaging, i.e. the materials which come into direct contact 113 with the product, is considered, being the object of the $\mathrm{C} 2 \mathrm{C}$ certification. The product system under 114 study includes the supply of raw materials, i.e. the aluminum alloys used for the lid ( $21 \%$ of the can 115 weight) and the body (79\% of the can weight), the manufacturing of the lid and body, as well as 116 their assembly, the filling of the can and its final EoL. The system boundaries are presented in 117 Figure 1: the main exclusions regard the distribution and use stages, since these are assumed 118 identical for all compared systems. The influence of transports on the overall environmental impact 119 of AlC systems cans is usually minor compared to the other life cycle stages, and the use stage, e.g. 120 refrigeration of the beverage, is typically not included as it is assumed that the beverage is 121 consumed shortly after the purchase (Amienyo and Azapagic 2016). 


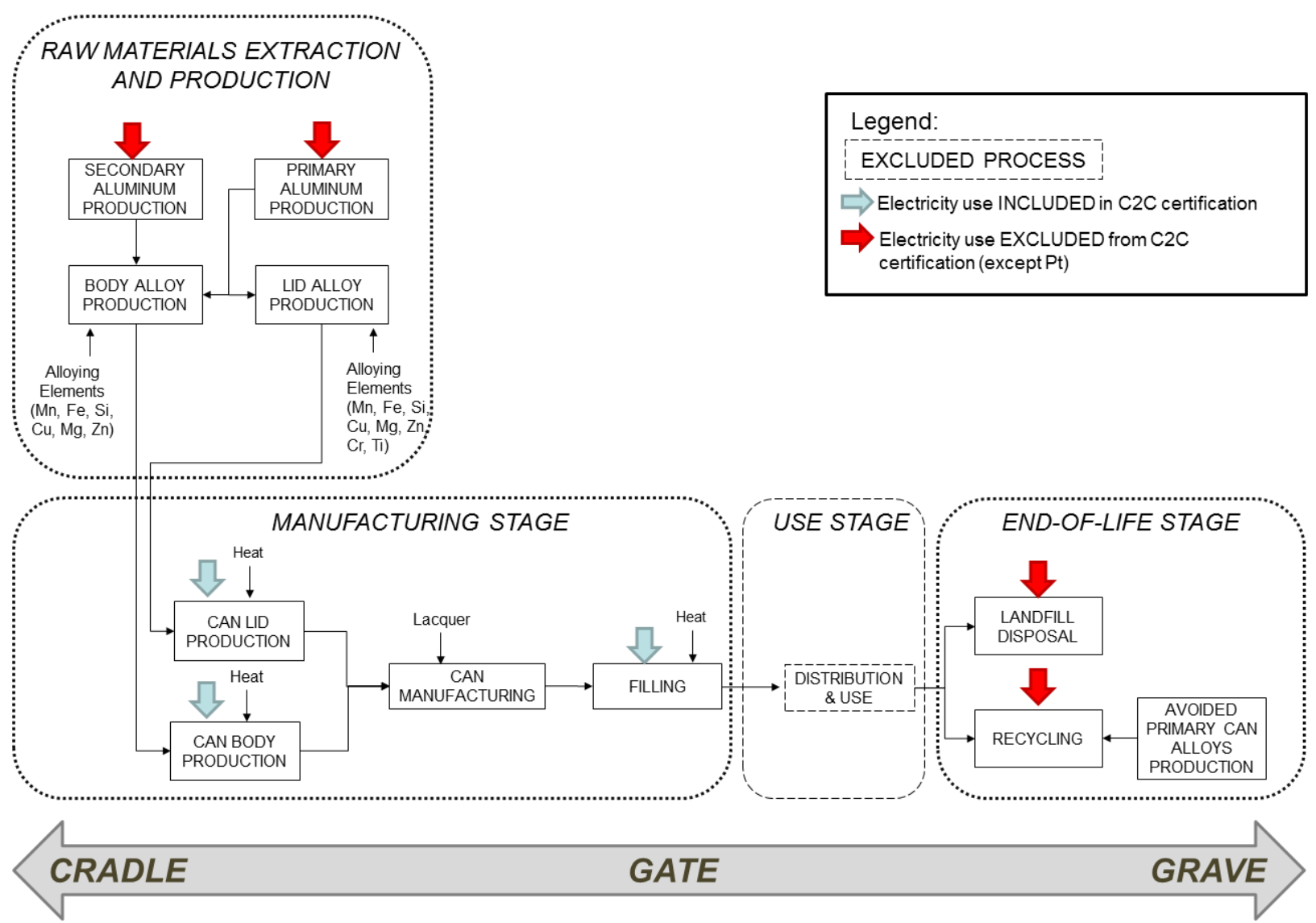

Figure 1. Life cycle stages of the aluminum can (AIC) system considered, with indication of main inputs and outputs; excluded processes are marked with dashed box. 


\section{<heading level 2> Data collection and system modelling}

In line with the identified decision context situation A of the ILCD guidelines (see previous section), the Life Cycle Inventory (LCI) modelling framework chosen is attributional with the use of system expansion to model process multi-functionality (EC-JRC-IES 2010). The ecoinvent 3.1 database (attributional default) was used to build the LCI (Weidema et al. 2013), considering the avoided impacts from the average market situation to model recycling at the EoL (EC-JRC-IES 2010). The LCI model was built in the LCA software SimaPro v.8.0.4.30 (PRé 2013). The foreground system was modelled with primary data, e.g. using electricity and heat consumption data from the filling facilities (Niero et al. 2016), while secondary data were used for modelling the background system, i.e. primary aluminum production (Stichling and Nguyen-Ngoc 2009), can manufacturing (e.g. lacquering (Li and Qiu 2013)) and the EoL management, which includes recycling and landfilling (Stichling and Nguyen-Ngoc 2009). We considered the current recycling rate for aluminum cans in UK (65\%) (EAA 2015), and an average \% of recycled content of $67.8 \%$ (PE Americas 2010). We used the default ecoinvent 3.1 datasets to model the input materials, i.e. average primary aluminum production both in Europe and China, secondary aluminum production, lacquer composition and EoL treatment. We modelled the can components, i.e. body and lid, according to their actual aluminum alloy composition: AA5182 for the lid and AA3004 for the body, respectively, as suggested in Niero and Olsen (2016). We considered the maximum threshold values of alloying elements allowed for the two abovementioned alloys (The University of Liverpool 2015). The main modifications to the default datasets in the scenario analysis consisted of changed energy input, i.e. the electricity used during manufacturing, primary aluminum production and recycling. 


\section{<heading level 2> The C2C requirement for RE\&CM}

The intention of the RE\&CM category of the $\mathrm{C} 2 \mathrm{C}$ certification program is "to provide a quantitative measure of the percentage of renewably generated energy that is utilized in the manufacture of the product. Purchased electricity and direct on-site emissions associated with the final manufacturing stage of the product, as well as embodied energy associated with the product from Cradle to Gate, are considered, depending on the level of certification" (Cradle to Cradle Products Innovation Institute 2016). The product under analysis is indeed graded based on quantitative parameters, e.g. the proportion of electricity coming from renewable sources (termed “\% RE" in the following) and the proportions of direct GHGs emissions which are offset (named "\% GHGs offset" in the following), and qualitative ones, e.g. the development of strategy for energy use and carbon management. Direct GHG emissions in scope for this requirement are those that are either emitted directly during the product's final manufacture or on-site treatment of process wastes or associated with purchased heat (Cradle to Cradle Products Innovation Institute 2016). We focus here on the quantitative aspects and consider the highest levels for the RE\&CM criterion, i.e. gold $(\mathrm{G})$ and platinum $(\mathrm{P})$, which are achieved if the manufacturing stage of the product (see Fig. 1), meets the two following conditions: (i) $50 \%$ (for gold) and $100 \%$ (for platinum) of purchased electricity is renewably sourced or offset with renewable energy projects, and (ii) the same proportions of direct on-site GHG emissions are offset (Cradle to Cradle Products Innovation Institute 2016). For the platinum level additional requirements apply that comprise the supply chain, and therefore a "cradle to gate" perspective (see Fig. 1): iii) the accounting of the embodied GHG emissions; (iv) the definition of a strategy to optimize the embodied GHG of the product; (v) the coverage of at least $5 \%$ of the embodied energy associated with the product (cradle to gate) by offsets or other mechanisms, e.g. projects with suppliers, product re-design, savings during the use phase (Cradle to Cradle Products Innovation Institute 2016). 
174

175

\section{<heading level 2> Scenarios definition}

In the development of the scenarios we refer to the $\% \mathrm{RE}$ in the electricity mix used for the life cycle stages included in the $\mathrm{C} 2 \mathrm{C}$ certification up to platinum level, i.e. body and lid manufacturing and filling, as well as the stages included only partially in the platinum level, i.e. primary aluminum production and excluded from the certification, i.e. the EoL, as shown in Fig. 1. Since can manufacturing and filling are assumed to take place in the UK, the electricity mix for UK was used taking the default ecoinvent 3.1 unit processes as a starting point. In the $\mathrm{C} 2 \mathrm{C}$ certification program, renewable electricity that is already a standard part of the grid mix does not count toward this requirement, "unless the applicant is participating in a voluntary green pricing program or the applicant has verified that their utility is delivering renewable electricity that may be claimed by the utility customer without being double-counted elsewhere in the system" (Cradle to Cradle Products Innovation Institute 2016). For the AlC system under study we assumed that the applicant is involved in a voluntary green pricing program. To take into account of the variability in renewable energy sources different scenarios, including different mixes of renewable electricity, were considered for the highest certification level, i.e. platinum. In terms of direct GHGs we accounted only for those associated with purchased heat by the utility during the manufacturing stage (Fig. 1) and deducted their contribution from the climate change impact category, according to the requirements set by the certification level (i.e. $50 \%$ for gold and $100 \%$ for platinum). No impacts generating from the actions undertaken to provide the offset are considered, therefore the case modelled represents the best case scenario. Table 1 provides an overview of all scenarios assessed in the study. The details of the datasets used in the LCI modelling for the electricity from RE, primary aluminum production and heat (from natural gas) are reported in Table S1, in the Supplementary Information (SI). 
Table 1 Summary of the 16 scenarios considered for the aluminum can (AIC) system, where EU refers reported in Table S1, in the Supplementary Information (SI).

\begin{tabular}{|c|c|c|c|c|}
\hline \multirow[t]{2}{*}{ Designation } & \multirow{2}{*}{$\begin{array}{l}\text { Scenario description (In } \\
\text { brackets the C2C } \\
\text { certification level) }\end{array}$} & \multirow{2}{*}{$\begin{array}{l}\text { Primary Al alloy } \\
\text { production }\end{array}$} & \multicolumn{2}{|c|}{ Manufacturing } \\
\hline & & & Electricity mix & $\begin{array}{c}\text { GHGs } \\
\text { offset }\end{array}$ \\
\hline 1-B-EU & $\begin{array}{l}\text { Baseline AlC system in } \\
\text { Europe }\end{array}$ & Default Europe & \multirow{2}{*}{$\begin{array}{l}\text { Current }(2015) \\
\text { UK el. mix }(21 \% \\
\text { RE })^{\mathrm{a}}\end{array}$} & - \\
\hline $1-\mathrm{B}-\mathrm{CN}$ & Baseline AlC system in China & Default China & & \\
\hline 2-C2C/G-EU & AlC in Europe (Gold) & Default Europe & \multirow{2}{*}{$\begin{array}{l}\text { Current } \begin{array}{r}(2015) \\
\text { UK el. mix } \\
\text { adjusted to } 50 \% \\
R^{\mathrm{B}}\end{array} \\
\end{array}$} & $50 \%$ \\
\hline $2-\mathrm{C} 2 \mathrm{C} / \mathrm{G}-\mathrm{CN}$ & AlC in China (Gold) & Default China & & $\begin{array}{l}\text { GHGs } \\
\text { from heat }\end{array}$ \\
\hline 3-C2C/P(2015UK)-EU & \multirow{2}{*}{$\begin{array}{l}\text { AlC in Europe (Platinum) with } \\
\text { current UK mix } \\
\text { AlC in China (Platinum) with } \\
\text { current UK mix }\end{array}$} & Default Europe & \multirow{2}{*}{$\begin{array}{l}\text { Current (2015) } \\
\text { UK el. mix } \\
\text { adjusted to } 100 \% \\
\mathrm{RE}^{\mathrm{c}}\end{array}$} & $100 \%$ \\
\hline 3-C2C/P(2015 UK)-CN & & Default China & & $\begin{array}{l}\text { GHGs } \\
\text { from heat }\end{array}$ \\
\hline 4-C2C/P(solar)-EU & \multirow{2}{*}{$\begin{array}{l}\text { AlC in Europe (Platinum) with } \\
100 \% \text { solar energy } \\
\text { AlC in China (Platinum) with } \\
100 \% \text { solar energy }\end{array}$} & Default Europe & \multirow{2}{*}{$\begin{array}{l}100 \% \text { solar energy } \\
\text { (single-Si) }\end{array}$} & $\begin{array}{l}100 \% \\
\text { GHGs }\end{array}$ \\
\hline 4-C2C/P(solar)-CN & & Default China & & from heat \\
\hline 5-C2C/P(wind)-EU & \multirow{2}{*}{$\begin{array}{l}\text { AlC in Europe (Platinum) with } \\
100 \% \text { wind energy } \\
\text { AlC in China (Platinum) with } \\
100 \% \text { wind energy }\end{array}$} & Default Europe & \multirow{2}{*}{$\begin{array}{l}100 \% \text { wind energy } \\
\text { (on-shore }>3 \mathrm{MW})\end{array}$} & $\begin{array}{l}100 \% \\
\text { GHGs }\end{array}$ \\
\hline $5-\mathrm{C} 2 \mathrm{C} / \mathrm{P}$ (wind) $-\mathrm{CN}$ & & Default China & & from heat \\
\hline 6-LC(2015 UK)-EU & \multirow{2}{*}{$\begin{array}{l}\text { AlC in Europe, current UK } \\
\text { mix (100\%RE) + life cycle } \\
\text { perspective for RE } \\
\text { AlC in China, current UK mix } \\
(100 \% \text { RE) + life cycle } \\
\text { perspective for RE }\end{array}$} & $\begin{array}{l}\text { Europe with } 100 \% \\
\text { RE }^{\mathrm{d}}\end{array}$ & \multirow{2}{*}{$\begin{array}{l}\text { Current (2015) } \\
\text { UK el. mix } \\
\text { adjusted to } 100 \% \\
\mathrm{RE}^{\mathrm{c}}\end{array}$} & $\begin{array}{l}100 \% \\
\text { GHGs } \\
\text { from heat }\end{array}$ \\
\hline 6-LC(2015 UK)-CN & & China with $100 \% \mathrm{RE}^{\mathrm{e}}$ & & \\
\hline \multirow{2}{*}{ 7-LC(solar)-EU } & \multirow{3}{*}{$\begin{array}{l}\text { AlC in Europe, (100\% solar)+ } \\
\text { life cycle perspective for RE } \\
\text { AlC in China, (100\% solar)+ } \\
\text { life cycle perspective for RE }\end{array}$} & Europe with $100 \%$ & \multirow{3}{*}{$\begin{array}{l}100 \% \text { solar energy } \\
\text { (single-Si) }\end{array}$} & \multirow{3}{*}{$\begin{array}{l}100 \% \\
\text { GHGs } \\
\text { from heat }\end{array}$} \\
\hline & & & & \\
\hline 7-LC(solar)-CN & & China with $100 \% \mathrm{RE}^{\mathrm{e}}$ & & \\
\hline \multirow[t]{3}{*}{ 8-LC(wind)-EU } & \multirow{3}{*}{$\begin{array}{l}\text { AlC in Europe, }(100 \% \text { wind }+ \\
\text { life cycle perspective for RE } \\
\text { AlC in China, }(100 \% \text { wind })+ \\
\text { life cycle perspective for RE }\end{array}$} & Europe with $100 \%$ & \multirow{3}{*}{$\begin{array}{l}100 \% \text { wind energy } \\
(\text { on-shore }>3 \mathrm{MW})\end{array}$} & \multirow{3}{*}{$\begin{array}{l}100 \% \\
\text { GHGs } \\
\text { from heat }\end{array}$} \\
\hline & & & & \\
\hline & & With $100 \% \mathrm{RE}^{\mathrm{c}}$ & & \\
\hline
\end{tabular}

${ }^{a}$ Based on UK-DECC (2014)

${ }^{\mathrm{b}}$ Based on the current (2015) mix distribution (UK-DECC 2014), but adjusted with 50\% RE, i.e. wind (34\%), heat and power co-generation from biogas (12\%) and biomass (2\%), hydro (2\%)

${ }^{\mathrm{c}}$ Based on the current (2015) mix distribution, but with adjusted with $100 \%$ RE, i.e. wind (67\%), heat and power co-generation from biogas $(23 \%)$ and biomass $(5 \%)$, hydro (5\%).

$207{ }^{\mathrm{d}}$ Modelled considering $80 \%$ hydropower and $20 \%$ wind power

${ }^{\mathrm{e}}$ Modelled considering $10 \%$ hydropower and $90 \%$ wind power 


\section{<heading level 3> Baseline scenarios}

For the baseline scenarios (1-B-EU, 1-B-CN) we considered the current UK electricity mix for the manufacturing processes based on the reference scenario described by the UK Department of Energy and Climate Change (UK-DECC 2014). This leads to the following distribution: hard coal (35\%), natural gas $(26 \%)$, nuclear $(17 \%)$, oil (1\%), wind (14\%), heat and power co-generation from biogas $(5 \%)$ and biomass (1\%), hydro (1\%). Overall, the share of RE is equal to $21 \%$.

\section{<heading level 3> Gold scenarios}

For the scenarios representing gold certification (2-C2C/G-EU, 2-C2C/G-CN), the relative distribution of each renewable and non-renewable energy source as in the current electricity mix were kept and adjusted so that the aggregated contributions of RE and non RE sources amount to 50:50\% of the modelled electricity mix, respectively. Therefore, the electricity mix considered is: hard coal $(22 \%)$, natural gas $(16.4 \%)$, nuclear $(11 \%)$, oil $(0.6 \%)$, wind $(34 \%)$, heat and power cogeneration from biogas (12\%) and biomass (2\%), hydro (2\%).

\section{<heading level 3> Platinum scenarios}

With regard to platinum certification, corresponding to $100 \% \mathrm{RE}$, different scenarios were built using: the current UK RE mix (for scenarios 3-C2C/P(2015UK)-EU and 3-C2C/P(2015 UK)-CN); $100 \%$ RE from solar energy (for 4-C2C/P(solar)-EU and 4-C2C/P(solar)-CN), represented by the single-Si panel technology (choice subject to limited data availability) and 100\% RE from wind source (5-C2C/P(wind)-EU; 5-C2C/P(wind)-CN), assuming on-shore wind technology, which currently is more mature and is foreseen to support a larger share of electricity generation than offshore wind power technology (IEA 2013). The selection of wind and solar power was motivated by their relatively lower reported environmental impacts, their anticipated role in future electricity generation landscapes and their contribution to energy security (Asdrubali et al. 2015; 
Hosenuzzaman et al. 2015). Moreover, to model the offset of 5\% of the embodied energy associated with the product, we reduced by $5 \%$ the electricity used in the manufacturing stage.

\section{<heading level 3> Life cycle scenarios}

For including the life cycle perspective from cradle to grave in the AlC system we considered additional sets of scenarios, built on the platinum certification level, but assuming an increase of RE for electricity in the raw materials extraction and production (i.e. prior to the manufacturing stage) and EoL stages (see Fig. 1). Primary aluminum production is very energy intensive, and hence the location of production plants is often determined by access to large amounts of cheap electricity, which often results in an electricity mix that is different from the general grid mix of the countries where the production plants are located, thus aluminum industry specific electricity markets were used (Moreno Ruiz et al. 2014). Therefore, we modified the electricity mix used in primary ingot production, as well as in the primary liquid aluminum production (including bauxite mine operations, Al hydroxide, Al oxide). We assumed that the current fraction of non-renewable energy (termed "non-RE" in the following) in the aluminum specific electricity markets, i.e. $20 \%$ for Europe and $90 \%$ for China, can be substituted with the most competitive RE source, i.e. on-shore wind power (IEA 2013). An extension to $100 \%$ RE from hydropower is not deemed realistic due to the already high exploitation of hydropower capacity in these regions, e.g. hydropower is already extensively developed and with little further expansion potential left in Europe (IEA 2012). This leads to electricity mixes of 80:20\% and 10:90\% hydropower (current share):wind power sources throughout primary aluminum production in Europe and China, respectively. These grid mixes, in particular that of China, should be regarded as explorative mixes as a share of $90 \%$ wind power in the electric mix in China would imply effective grid management systems including storage capacity, which are not encompassed in this study due to lack of data.

\section{<heading level 2> Life Cycle Impact Assessment and sensitivity analysis}


262 The life cycle impact assessment (LCIA) was performed using the ILCD 2011 recommended methodology v1.05 (Hauschild et al. 2013) as embedded in SimaPro LCA software (PRé Consultants, 2015). The covered impact categories include climate change (CC), stratospheric ozone depletion (OD), human toxicity, considering both cancer effects (HT-c) and non-cancer effects (HT-nc), particulate matter (PM), ionizing radiation impacting human health (IR-HH), photochemical ozone formation (POF), acidification (Ac), terrestrial eutrophication (TE), freshwater eutrophication (FE), marine eutrophication (ME), freshwater ecotoxicity (FET), water use (WU), land use (LU) and resource depletion (RD), including mineral, fossil and renewable resources. To assess water use, significant advances have been made since the review of the methods leading to the ILCD recommendations was conducted; the water scarcity index (WSI) method developed by Pfister and colleagues (2009) was thus considered instead. Furthermore, given the focus on the energy aspect we considered the non RE Cumulative Energy Demand (CED) v1.09 (Frischknecht et al. 2007) as an LCI indicator since it has been proven to provide insights for product comparison in the beverage packaging sector (Scipioni et al. 2013). To illustrate the differences observed between the different scenarios for each impact category, we performed 'division-by-baseline' internal normalization, i.e. dividing results obtained for a given impact category for each scenario by the corresponding impact results of the baseline scenario (thus taken as a reference) (Laurent and Hauschild 2015). This enables to quantify the impact reductions brought by the implementation of the different scenarios compared to the baseline scenario. We assumed a cut-off of $10 \%$ to identify a significant difference among the alternatives, following e.g. Humbert et al. (2009); this cut-off was arbitrarily defined and does not necessarily reflect the actual uncertainty assessment. As a sensitivity check at the impact assessment level, a different LCIA methodology, i.e. ReCiPe 2008 midpoint, hierarchist v.1.11 (Goedkoop et al. 2009) was 285 additionally used. 
The detailed characterized impact scores for the aluminum can system are reported in Table S2 and S3 for Europe and China, respectively in the SI. Table 2 reports the normalized results of the progression from the baseline to the $\mathrm{C} 2 \mathrm{C}$ gold and platinum grades and "life cycle" scenarios (as defined in Table 1) for $4.22 \mathrm{~kg}$ of aluminum cans manufactured in the UK with primary aluminum produced in Europe. Normalized impact results for China are reported in a similar way in Table S4 in the SI.

Table 2 Normalized impact scores for the aluminum can system (indexed based on the baseline scenario) according to different $\mathrm{C} 2 \mathrm{C}$ certification levels and scenarios defined in Table 1 (Europe). The color coding is used to indicate the ranking of the scenarios, where the option with higher environmental impact are marked with red and the one with the lower environmental impact are marked with green, according to the following legend: above 1.10 (dark red); 1.00-1.09 (red); 0.90-0.99 (orange); 0.80-0.89 (dark yellow); 0.70-0.79 (yellow); 0.60-0.69 (light green); 0.50-0.59 (green); below 0.49 (dark green). Results for China are provided in Table $\mathrm{S4}$.

\begin{tabular}{|c|c|c|c|c|c|c|c|c|}
\hline Impact category & $\begin{array}{c}\text { 1- } \\
B \\
\text {-EU }\end{array}$ & $\begin{array}{c}2- \\
\mathrm{C} 2 \mathrm{C} / \mathrm{G} \\
-\mathrm{EU}\end{array}$ & $\begin{array}{c}3- \\
\text { C2C/P } \\
(2015 U K) \\
\text {-EU }\end{array}$ & $\begin{array}{c}\text { 4- } \\
\text { C2C/P } \\
\text { (solar) } \\
\text {-EU }\end{array}$ & $\begin{array}{c}5- \\
\mathrm{C2C} / \mathrm{P} \\
\text { (wind) } \\
-\mathrm{EU}\end{array}$ & $\begin{array}{c}\text { 6- } \\
\text { LC } \\
(2015 U K) \\
-E U\end{array}$ & $\begin{array}{c}\text { 7- } \\
\text { LC } \\
\text { (solar) } \\
\text {-EU }\end{array}$ & 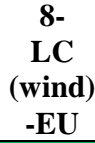 \\
\hline Climate change (CC) & 1.00 & 0.78 & 0.54 & 0.54 & 0.53 & 0.47 & 0.47 & 0.46 \\
\hline Ozone depletion (OD) & 1.00 & 0.99 & 0.97 & 0.99 & 0.96 & 0.91 & 0.93 & 0.90 \\
\hline Human toxicity, cancer (HT-c) & 1.00 & 1.00 & 1.01 & 1.00 & 1.00 & 1.01 & 1.01 & 1.00 \\
\hline Human toxicity, non cancer (HT-nc) & 1.00 & 0.99 & 0.98 & 1.01 & 0.99 & 0.97 & 1.00 & 0.98 \\
\hline Particulate matter (PM) & 1.00 & 0.99 & 0.96 & 0.98 & 0.95 & 0.86 & 0.87 & 0.84 \\
\hline $\begin{array}{l}\text { Ionizing radiation, human health } \\
\text { (IR-HH) }\end{array}$ & 1.00 & 0.94 & 0.83 & 0.84 & 0.82 & 0.62 & 0.62 & 0.61 \\
\hline $\begin{array}{l}\text { Photochemical Ozone Formation } \\
\text { (POF) }\end{array}$ & 1.00 & 0.98 & 0.94 & 0.94 & 0.92 & 0.87 & 0.87 & 0.85 \\
\hline Acidification $(\mathrm{Ac})$ & 1.00 & 0.97 & 0.93 & 0.93 & 0.91 & 0.84 & 0.85 & 0.82 \\
\hline Terrestrial Euthrophication (TE) & 1.00 & 0.98 & 0.95 & 0.92 & 0.90 & 0.87 & 0.85 & 0.82 \\
\hline Freshwater Eutrophication (FE) & 1.00 & 0.99 & 0.98 & 1.00 & 0.98 & 0.89 & 0.91 & 0.89 \\
\hline Marine eutrophication (ME) & 1.00 & 1.00 & 1.01 & 0.91 & 0.89 & 0.93 & 0.83 & 0.81 \\
\hline Freshwater Ecotoxicity (FET) & 1.00 & 1.02 & 1.05 & 1.00 & 0.99 & 1.04 & 0.99 & 0.98 \\
\hline Land Use (LU) & 1.00 & 1.05 & 1.14 & 0.93 & 0.92 & 1.13 & 0.92 & 0.91 \\
\hline Resource depletion (RD) & 1.00 & 1.00 & 1.01 & 1.06 & 1.00 & 1.01 & 1.06 & 1.01 \\
\hline $\begin{array}{l}\text { Non Renewable Cumulative Energy } \\
\text { Demand (Non-RE CED) }\end{array}$ & 1.00 & 0.97 & 0.91 & 0.92 & 0.90 & 0.82 & 0.83 & 0.81 \\
\hline Water Scarcity Index (WSI) & 1.00 & 1.04 & 1.10 & 1.01 & 0.93 & 1.07 & 0.98 & 0.90 \\
\hline
\end{tabular}




\section{<heading level 2> What environmental impact reductions can $\mathrm{C} 2 \mathrm{C}$ certification achieve?}

Only considering the scenarios relating to the $\mathrm{C} 2 \mathrm{C}$ certification, i.e. scenarios 2-5, a common trend across the different certification scenarios can be identified for the impact categories in Table 2, which can be divided in three groups. A first group includes IR-HH and CC, which present significant reductions among scenarios $2-5$, i.e. $22 \%$ for gold and ca $45 \%$ for platinum. A second group includes OD, PM, POF, Ac, TE, FE, ME, non RE CED which shows a slightly decreasing but not significant reduction in impact scores from the baseline towards gold and platinum certification (i.e. below 10\%). The third group includes the toxicity related and resource-related impact categories, i.e. HT-c, HT-nc, FET, LU, RD and WSI, which show a slightly increasing difference (maximum 14\% for LU) towards the higher certification levels, except for the last platinum scenario (i.e. number 5).

The marginal impact reduction (except for $\mathrm{CC}$ and $\mathrm{IR}-\mathrm{HH}$ ) across the $\mathrm{C} 2 \mathrm{C}$ certification scenarios can be explained by the contribution analysis per life cycle stage for the baseline scenario (Fig. 2a), the gold certification scenario (Fig. 2b), and the platinum certification scenario considering $100 \%$ wind energy during manufacturing (i.e. the platinum scenarios with lower impacts; Fig. 2c). The positive contribution of the electricity use to environmental impacts during manufacturing, i.e. the one included in the $\mathrm{C} 2 \mathrm{C}$ certification, is negligible compared to the contributions from heat during manufacturing and from lid and body alloys production, which include all the upstream processes such as alumina refining and electrolysis. These three life cycle stages thus represent the hotspots across all impact categories, as reported in the most recent LCA of primary aluminum production, which identified electricity and thermal energy as the factors responsible for the large contribution of alumina refining and electrolysis to GHGs emissions (Nunez and Jones 2015). The negative values observed in Fig. 2 refer to the End-of-life phase, namely to the avoided environmental impacts due to recycling. 
A

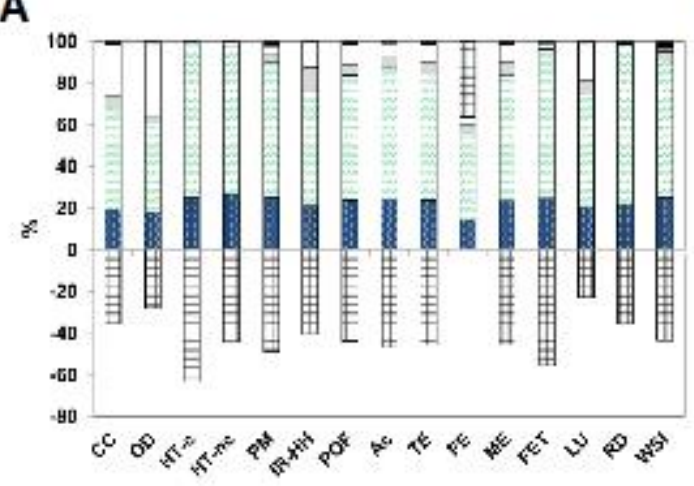

C

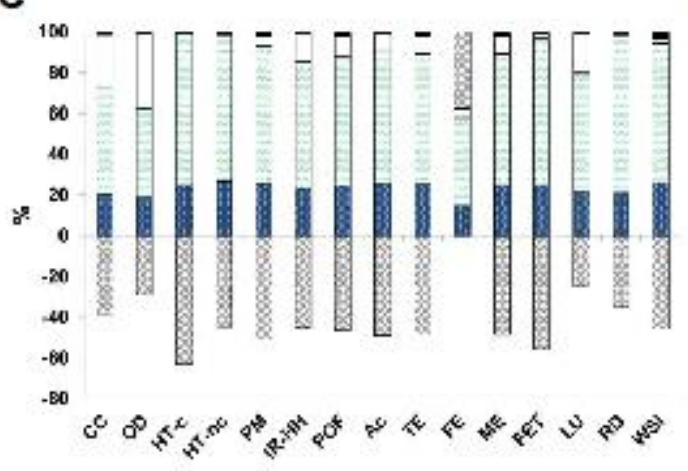

B

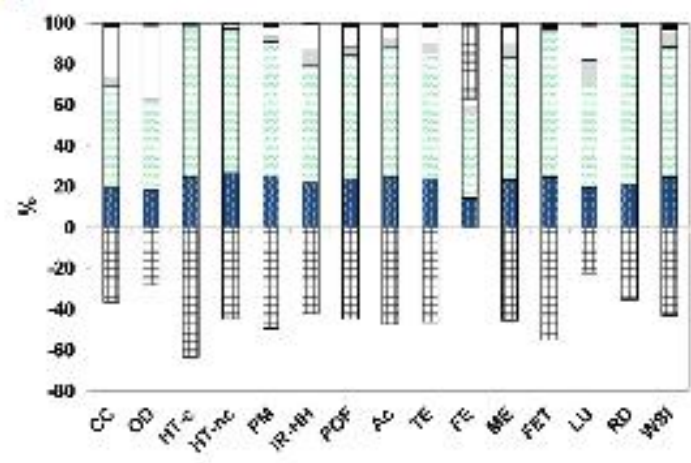

D

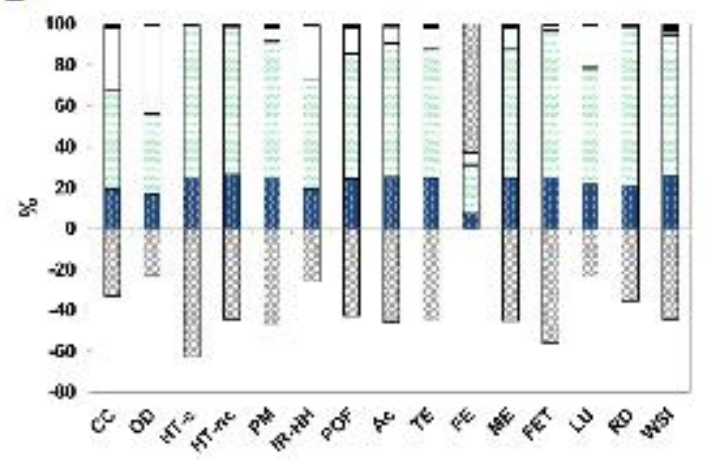

\section{BEnd-of-lifo}

- Lacquer manufacturing

Manufacturing - heat

$\square$ Manufacturing - electricity

$\square$ Body alloy production incl. RE

- Lid alloy production incl. RE

Figure 2 Contribution analysis for a selection of scenarios relative to Europe A) 1-B include all the upstream processes, as presented in Figure 1. 


\section{<heading level 2> Importance of including a full life cycle perspective in RE\&CM criterion}

The normalized impact results for scenarios 6-8 indexed on the baseline scenario are presented in Table 2 (for EU) and Table S4 in the SI (for CN). They reflect the changes when including a full life cycle perspective, i.e. from cradle to grave, for electricity use in the AlC systems. The same trends can overall be identified for EU and CN, with some discrepancies. Significant deviations of the environmental impacts from the baseline (i.e. higher than 10\%) are generally observed, with the exceptions of OD and HT-nc (for EU), for which the decrease is below the cut-off, and HT-c, FET, RD and LU (except 6-LC(2015UK)-EU), for which relatively negligible increases in the environmental impacts can overall be observed. For RD, the increase is mainly due to an increased metal extraction specific to PV, as confirmed by the sensitivity analysis performed with ReCiPe, which distinguishes between fossil and metal depletion, see Tables S5 and S6. For WSI, the inclusion of renewable energy highly based on hydropower in the primary $\mathrm{Al}$ production (scenarios 6) causes an increase of the environmental impact compared to the other scenarios with lower shares of hydropower (i.e. scenarios 7 and 8).

For the remaining impact categories, the deviations from the baseline are different between EU and CN scenarios. For EU, the impact categories PM, POF, Ac, TE, FE, ME and non RE CED show a moderate reduction (up to $20 \%$ ) in impact scores from the baseline towards the "LC scenarios", meanwhile for $\mathrm{CN}$ the decrease is up to $40-60 \%$. For CC the decrease from P-scenarios to LCscenarios is negligible (i.e. less than 10\%) for EU, but relevant for $\mathrm{CN}$ (i.e. around 50\%). This decrease is due to the contribution of the GHGs offset for the thermal energy, which is comparable in magnitude to the $\mathrm{CC}$ impact score from cradle to grave for $\mathrm{CN}$, but not for EU. For IR-HH a consistent decrease of the impact score is shown for EU, but no differences can be detected for $\mathrm{CN}$ due to the absence of nuclear energy in the electricity mix considered for Chinese primary aluminum production. No strong influence in terms of RE electricity source used can be detected 
with regard to the manufacturing stage, since the impact deriving from the other life cycle stages is much higher.

The trend reported in Table 2 confirms the importance of considering a broader range of environmental impacts alongside climate change, already reported for the specific UK case by Kouloumpis and colleagues (2015) and also at the global scale by Laurent and Espinosa (2015). Kouloumpis and colleagues (2015) concluded that in the UK case a decarbonisation of electricity supply to meet the 2050 carbon targets would lead to a reduction in the majority of the life cycle impacts by 2070, including climate change, with the exception of resource depletion, which would increase by 4-145 times on today's value, and health impact from radiation which would increase four-fold if nuclear power is used and electricity demand grows strongly (Kouloumpis et al. 2015). Moreover, the selection of the RE source could have some implications on the potential for impact reduction, even though in our case the deviations across platinum scenarios and "LC scenarios" are below $10 \%$. The sensitivity analysis performed using a different LCIA method, i.e. ReCiPe 2008 (midpoint, hierarchist v.1.11), confirmed the results obtained with the ILCD recommended method for all impact categories (see detailed explanation in Table S5 in the SI)

When switching from the baseline to the LC-scenarios, the reduction in terms of non RE CED is not significant for EU and moderate for CN (see Tables 2 and S4). Figure 3 represents the CED results for renewable and non-renewable energy results for the 16 scenarios analyzed, in the case of primary Al from Europe (Fig. 3a and 3c) and China (Fig. 3b and 3d). 
A

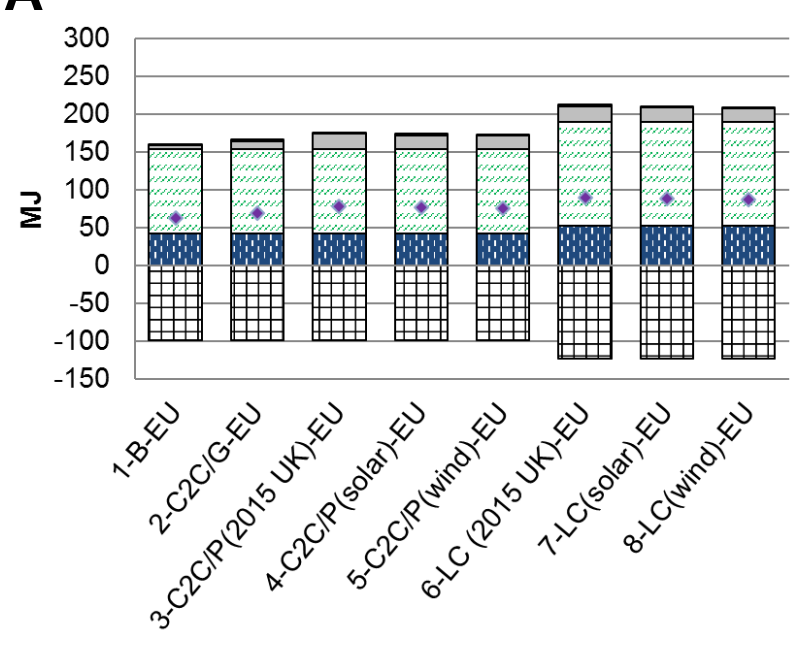

C

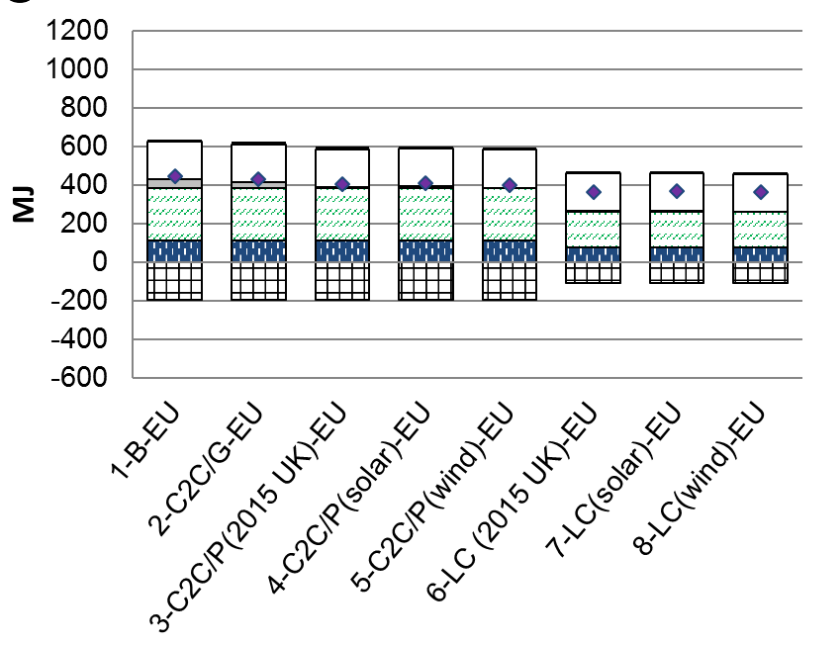

B

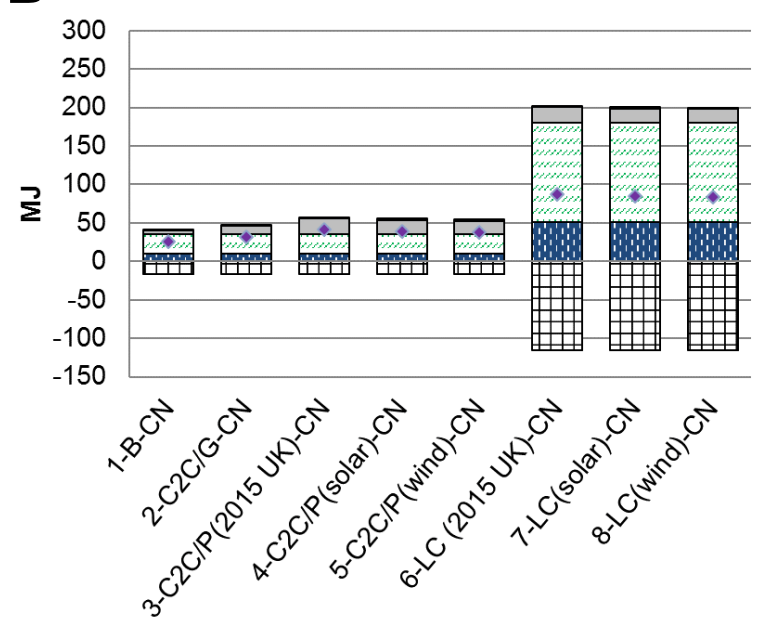

D

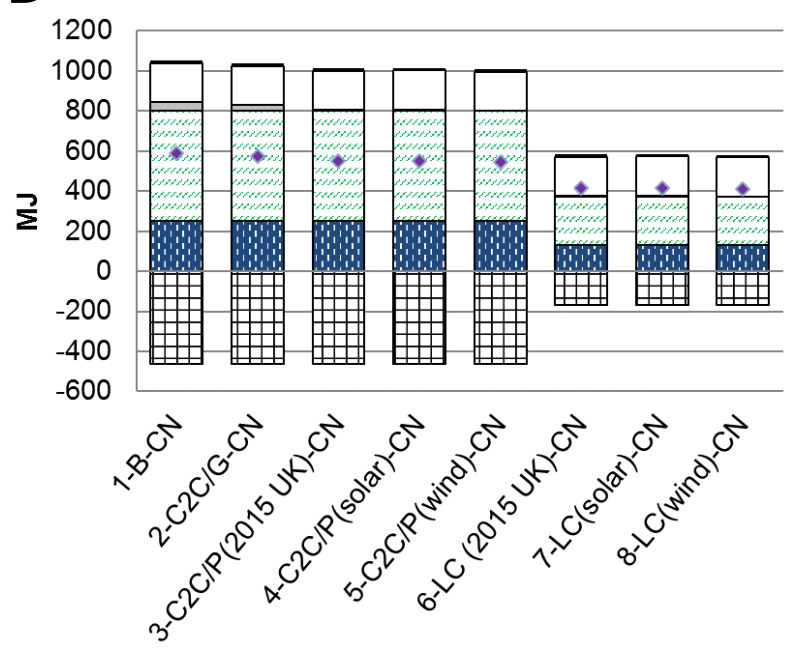

$\boxplus$ End-of-life

- Lacquer manufacturing

$\square$ Manufacturing - heat

$\square$ Manufacturing - electricity

Body alloy production

嘈 Lid alloy production

- Total systems according to the scenarios presented in Table 1, with distinction between renewable energy for (A) EU and (B) CN and non-renewable energy for (C) EU and (D) CN. 
The contribution analysis displayed in Fig. 3 shows that a considerable share of non RE comes from the heat used in the manufacturing stage. Despite the use of electricity from RE in the primary Al production in the LC scenarios, the share of non-renewable energy still dominates the CED, due to 384 the contribution from the non-fossil component (e.g. natural gas and coal) used for heating and in 385 non RE sources.

\section{<heading level $1>$ Conclusions and recommendations}

The outcomes of the LCA-based scenario analysis showed that compliance with the current

RE\&CM C2C certification requirement offers limited benefits in terms of reduced environmental impacts for the AlC system considered. Although there are slight differences between the EU and $\mathrm{CN}$ scenarios, the observed trends are the same: with the exception of CC impacts, the reduction in potential environmental impacts that can be achieved at the highest certification levels (gold and platinum) is negligible compared to the potential for reduction that the LC perspective can bring. The recently-updated RE\&CM criterion includes a partial life cycle perspective - only at the exceed the environmental benefits brought up by the $\mathrm{C} 2 \mathrm{C}$ certification, not only for $\mathrm{CC}$, but for the broader range of impact categories. The impacts from thermal energy are currently dealt in terms of direct on-site GHGs emissions, which need to be offset to achieve the highest $\mathrm{C} 2 \mathrm{C}$ certification 
level. In our study we have not modelled the impacts originating from the offset activities, which could further limit the benefits in terms of environmental impacts reduction from the baseline to the $\mathrm{C} 2 \mathrm{C}$ certification scenarios and potentially also lead to increases of impacts.

Our findings show that for product systems where most of the environmental impacts come from raw material extraction and production, the RE share in the upstream processes need to be taken into account in the product optimization strategy, not only in terms of electricity but also thermal energy production, which has a significant contribution in terms of non RE CED (see Fig.3c and Fig. 3d). From a company perspective, this means that the knowledge of the raw material supplier location is crucial for achieving better environmental performances and higher certification levels.

However, when the $\mathrm{C} 2 \mathrm{C}$ certification refers to a specific market, knowing the location at country level might be insufficient, e.g. for China, where the different Chinese provinces present a wide range of grid mixes and disparities in GHG emission intensities from primary aluminum production (Hao et al. 2015). If the location of the plant is known, the recommendation is thus to adjust the level of details during data collection to be able to model the local energy mix, if relevant, e.g. considering ecoinvent v3.2, which includes electricity production at the province level for China (Moreno Ruiz et al. 2015). Moreover, a huge margin for reducing the electricity consumption for aluminum production, is provided by the use of secondary aluminum (Hao and colleagues 2015), since only $5 \%$ of the energy used for primary aluminum is required to make secondary aluminum (EAA 2013). Particularly for Chinese Al production, GHG mitigation strategies should be based on developing secondary aluminum industry, improving energy mix and optimizing resource efficiency of production (Liu et al. 2016). Therefore, an increase in the recycled content of aluminum products (measured in terms of $\mathrm{MR}$ requirement in the $\mathrm{C} 2 \mathrm{C}$ certification) could positively affect the RE criterion (Niero et al. 2016).

According to the $\mathrm{C} 2 \mathrm{C}$ certification program, all eligible renewable energy sources, i.e. solar, wind, hydropower, biomass (when not in competition with food supplies), geothermal and hydrogen fuel cells, are given the same preference although these renewable energy sources differ in their 
environmental performances, see e.g. Asdrubali et al. (2015). In the case of aluminum cans, due to the negligible contribution of electricity during manufacturing, no significant differences between the different RE sources were detected (see results for the different platinum scenarios). However, in other settings the selection of an energy source might be influential on the overall environmental performances of the system; such influences need to be further investigated. In the decision making process, the limitations of the LCA results should not be overlooked, e.g. the uncertainty associated to results due to assumptions made and to the LCIA characterization models.

As shown by Haas and colleagues (2015) in their assessment of material flows, waste production, and recycling in the European Union and the world in 2005, reducing the consumption of fossil energy carriers is necessary to further raise the degree of circularity of the economy. Our results confirm that the role of an energy transition from fossil to renewable energy resources should not be neglected in shifting towards a circular economy. Decisions at the company level present repercussions on the global scale: switching from fossil to renewable energy sources for aluminum production could induce effects on electricity infrastructures and other industrial sectors, and potentially lead to burden shifting due to the constrained supply of renewable energy. The environmental consequences of such a large scale change should therefore be assessed by means of a broader LCA incorporating the changes with structural market implications beyond the foreground- system, considering decision context situation B of the ILCD guidelines. Deploying renewable energy sources to produce electricity and heat for use at industrial scale is in the long term the only possible solution to implement the ideal C2C platinum scenario, with $100 \%$ renewable energy use. The possibility to use green certificates to achieve the $\mathrm{C} 2 \mathrm{C}$ requirement stimulates the demand for renewable energy, but this is not a consistent long term solution to put into practice the use of "current solar income" principle. The selection of the perspective on the use of renewable energy is crucial to avoid burden shifting and assure a true environmental impact reduction, although the technical challenges at large production scale should be incorporated in the decision making process. In the case of products, such as aluminum cans, where most of the 
environmental impacts do not originate from the manufacturing stage of the final products, but from the raw material extraction and production, the efforts should be directed to the upstream processes. This conclusion can be extended for all products where raw materials extraction is the most impacting life cycle stage, e.g. laminated carton containers (Scipioni et al. 2013), plastic containers (Madival et al. 2009), stainless steel building components (Ibbotson and Kara 2013), metallic furniture (Babarenda Gamage et al. 2008), etc.

LCA allows modeling the consequences of decisions not only at the product level but also on a large scale, e.g. through consequential LCA. Moreover, since the overall environmental performances of a product depend not only on the manufacture of the product itself, but on the whole life cycle, see e.g. the impact from refrigeration of beverages in certain geographical contexts, the limited focus of the $\mathrm{C} 2 \mathrm{C}$ certification on the product can therefore benefit from the inclusion of a broader life cycle perspective. There has recently been a discussion whether C2C certified products are better from an environmental point of view, see Llorach-Massana and colleagues (2015) and the rebuttal by Kausch and Klosterhaus (2015). The primary aim of the C2C design framework is to provide guidelines for product quality and innovation, and not strictly to communicate the environmental issues associated with a product. However, considering that the $\mathrm{C} 2 \mathrm{C}$ certification program is used also as a means of marketing towards consumers, caution is needed when communicating the environmental performances of $\mathrm{C} 2 \mathrm{C}$ certified products. We believe that the current focus of the RE\&CM criterion on the $\mathrm{CC}$ impact is too narrow for modelling the actual environmental impact deriving from the use of renewables. Our results confirmed that GHG emissions could not be used as a single indicator to represent the environmental performance of a system or technology (Turconi et al. 2013; Laurent et al. 2012). Even though the use of LCA in a C2C certification context is constrained by the limited availability of datasets representing future energy technologies, therefore preventing the modelling of long term forecasting scenarios, our main recommendation is to combine the $\mathrm{C} 2 \mathrm{C}$ certification with LCA to make the second $\mathrm{C} 2 \mathrm{C}$ principle operational. The adoption of scenarios analysis in an LCA context 
483

can support the $\mathrm{C} 2 \mathrm{C}$ certification program with a tool to compare the environmental performances of alternative improvement strategies which can be implemented in the progression towards higher certification levels.

\section{Acknowledgements}

The authors would like to thank Carlsberg Foundation for funding the postdoc project 'Design of Cradle to Cradle ${ }^{\circledR}$ - Inspired System for Beer Beverage Packaging”. We would also like to thank the three anonymous reviewers for their suggestions on how to improve the readability and clarity of the paper.

\section{References}

Allacker, K., F. Mathieux, S. Manfredi, N. Pelletier, C. De Camillis, F. Ardente, and R. Pant. 2014. Allocation solutions for secondary material production and end of life recovery: Proposals for product policy initiatives. Resources, Conservation and Recycling 88: 1-12. http://linkinghub.elsevier.com/retrieve/pii/S0921344914000834.

Amienyo, D. and A. Azapagic. 2016. Life cycle environmental impacts and costs of beer production and consumption in the UK. The International Journal of Life Cycle Assessment 2014(Bbpa 2015). http://link.springer.com/10.1007/s11367-016-1028-6.

Asdrubali, F., G. Baldinelli, F. D’Alessandro, and F. Scrucca. 2015. Life cycle assessment of electricity production from renewable energies: Review and results harmonization. Renewable and Sustainable Energy Reviews 42: 1113-1122. http://linkinghub.elsevier.com/retrieve/pii/S1364032114009071.

Babarenda Gamage, G., C. Boyle, S.J. McLaren, and J. McLaren. 2008. Life cycle assessment of commercial furniture: A case study of Formway LIFE chair. International Journal of Life Cycle Assessment 13(5): 401-411.

Bjørn, A. and M.Z. Hauschild. 2013. Absolute versus Relative Environmental Sustainability. Journal of Industrial Ecology 17(2): 321-332. http://doi.wiley.com/10.1111/j.15309290.2012.00520.x.

Cradle to Cradle Products Innovation Institute. 2016. Cradle to Cradle Certified Product Standard Version 3.1. http://s3.amazonaws.com/c2cwebsite/resources/certification/standard/C2CCertified_Product_Standard_V3_Nov_4_2013.pd f.

Dolan, S.L. and G.A. Heath. 2012. Life Cycle Greenhouse Gas Emissions of Utility-Scale Wind Power: Systematic Review and Harmonization. Journal of Industrial Ecology 16(SUPPL.1). 
EC. 2013. Commission Recommendation of 9 April 2013 on the use of common methods to measure and communicate the life cycle environmental performance of products and organisations. Vol. 50. European Commission, Brussels.

EC. 2015. COM (2015) 614 Communication from the Commission to the European Parliament, the Council, the European Economic and Social Committee and the Committee of the Regions. Closing the loop - An EU action plan for the Circular Economy. http://ec.europa.eu/environment/circular-economy/index_en.htm.

EC-JRC-IES. 2010. ILCD Handbook - General guide on LCA - Detailed guidance. Euroepan Commission. Joint Research Centre. Institute for Environment and Sustainability. First edit. Vol. 15. European Union.

EMF. 2013. Towards the circular economy. Opportunities for the consumer goods sector. Ellen MacArthur Foundation.

EAA. 2013. Environmental Profile Report for the European Aluminium Industry April 2013- Data for the year 2010 Life Cycle Inventory data for aluminium production and transformation processes in Europe. European Alluminium Association.

EAA. 2015. Press Release. Recycling rate for cans at new record level. http://europeanaluminium.eu/media/1285/201503_recycling-rate-for-cans-at-new-recordlevel_europeanaluminium.pdf. Accessed June 14, 2016.

Frischknecht, R., N. Jungbluth, H.-J. Althaus, G. Doka, T. Heck, S. Hellweg, R. Hischier, and colleagues. 2007. Overview and Methodology. Ecoinvent Report No. 1. Swiss Centre for Life Cycle Inventories. Dübendorf, Switzerland.

Goedkoop, M., R. Heijungs, M. Huijbregts, A. De Schryver, J. Struijs, and van Z. R. 2009. ReCiPe 2008, A life cycle impact assessment method which comprises harmonised category indicators at the midpoint and the endpoint level. http://www.lcia-recipe.net.

Hao, H., Y. Geng, and W. Hang. 2015. GHG emissions from primary aluminum production in China: Regional disparity and policy implications. Applied Energy(800). http://linkinghub.elsevier.com/retrieve/pii/S030626191500687X.

Harst, E. van der, J. Potting, and C. Kroeze. 2016. Comparison of different methods to include recycling in LCAs of aluminium cans and disposable polystyrene cups. Waste Management 48: 565-583. http://www.sciencedirect.com/science/article/pii/S0956053X15301367.

Hauschild, M.Z., M. Goedkoop, J. Guinée, R. Heijungs, M. Huijbregts, O. Jolliet, M. Margni, and colleagues. 2013. Identifying best existing practice for characterization modeling in life cycle impact assessment. The International Journal of Life Cycle Assessment 18(3): 683-697. http://link.springer.com/10.1007/s11367-012-0489-5.

Hertwich, E.G., T. Gibon, E.A. Bouman, A. Arvesen, S. Suh, G.A. Heath, J.D. Bergesen, A. Ramirez, M.I. Vega, and L. Shi. 2014. Integrated life-cycle assessment of electricity-supply scenarios confirms global environmental benefit of low-carbon technologies. Proceedings of the National Academy of Sciences of the United States of America 112(20): 6277-6282. http://www.scopus.com/inward/record.url?eid=2-s2.0-84929404255\&partnerID=tZOtx3y1.

Hosenuzzaman, M., N. a. Rahim, J. Selvaraj, M. Hasanuzzaman, a. B.M. a. Malek, and a. Nahar. 2015. Global prospects, progress, policies, and environmental impact of solar photovoltaic power generation. Renewable and Sustainable Energy Reviews 41: 284-297. http://linkinghub.elsevier.com/retrieve/pii/S1364032114007229.

Hsu, D.D., P. O’Donoughue, V. Fthenakis, G.A. Heath, H.C. Kim, P. Sawyer, J.K. Choi, and D.E. 
Turney. 2012. Life Cycle Greenhouse Gas Emissions of Crystalline Silicon Photovoltaic Electricity Generation: Systematic Review and Harmonization. Journal of Industrial Ecology 16(SUPPL.1).

Humbert, S., V. Rossi, M. Margni, O. Jolliet, and Y. Loerincik. 2009. Life cycle assessment of two baby food packaging alternatives: Glass jars vs. plastic pots. International Journal of Life Cycle Assessment 14(2): 95-106.

Haas, W., F. Krausmann, D. Wiedenhofer, and M. Heinz. 2015. How Circular is the Global Economy?: An Assessment of Material Flows, Waste Production, and Recycling in the European Union and the World in 2005. Journal of Industrial Ecology 0(0): n/a-n/a. C:IUsers $\backslash$ helbichr\Dropbox \ReadCube Journal of Industrial Ecology 2015 Haas W.pdflnhttp://dx.doi.org/10.1111/jiec.12244 VN readcube.com/nhttp://dx.doi.org/10.1111/jiec.12244\nhttp://doi.wiley.com/10.1111/jiec.12244.

Ibbotson, S. and S. Kara. 2013. LCA case study. Part 1: Cradle-to-grave environmental footprint analysis of composites and stainless steel I-beams. International Journal of Life Cycle Assessment 18(1): 208-217.

IEA. 2012. Technology Roadmap. Hydropower. OECD/IEA. http://www.springerreference.com/index/doi/10.1007/SpringerReference_7300.

IEA. 2013. Technology roadmap - Wind energy. International Energy Agency.

ISO. 2006a. Environmental management. Life cycle assessment. Principle and framework. ISO 14040:2006. Vol. 44. Geneva, Switzerland.

ISO. 2006b. Environmental management. Life cycle assessment. Requirements and guidelines. ISO 14044:2006. Vol. 44. Geneva, Switzerland.

Kausch, M.F. and S. Klosterhaus. 2015. Response to "Are Cradle to Cradle certified products environmentally preferable? Analysis from an LCA approach." Journal of Cleaner Production. http://www.sciencedirect.com/science/article/pii/S0959652615000360.

Kouloumpis, V., L. Stamford, and A. Azapagic. 2015. Decarbonising electricity supply: Is climate change mitigation going to be carried out at the expense of other environmental impacts? Sustainable Production and Consumption 1(April): 1-21. http://linkinghub.elsevier.com/retrieve/pii/S2352550915000020.

Laurent, A. and N. Espinosa. 2015. Environmental impacts of electricity generation at global, regional and national scales in 1980-2011: what can we learn for future energy planning? Energy Environ. Sci. 8(3): 689-701. http://pubs.rsc.org/en/content/articlehtml/2015/ee/c4ee03832k.

Laurent, A. and M.Z. Hauschild. 2015. Normalization. In Life Cycle Impact Assessment, LCA Compendium - The Complete World of Life Cycle Assessment, ed. by M.Z. Hauschild and M.A.J. Huijbregts, 271-300. Dordrecht, NL: Springer. http://www.springerlink.com/index/M5342P55737M7016.pdflnhttp://www.cs.ucsb.edu/ chon g/290N-W10/EPAonLCA2006.pdf.

Laurent, A., S. Olsen, and M. Hauschild. 2012. Limitations of carbon footprint as indicator of environmental sustainability. Environmental Science \& Technology 46: 4100-4108.

Li, N. and K. Qiu. 2013. Study on delacquer used beverage cans by vacuum pyrolysis for recycle. Environmental Science \& Technology 47(20): 11734-8. http://www.ncbi.nlm.nih.gov/pubmed/24070094. 
604

605

606

607

608

609

610

611

612

613

614

615

616

617

618

619

620

621

622

623

624

625

626

627

628

629

630

631

632

633

634

635

636

637

638

639

640

641

642

643

644

645

Liu, G. and D.B. Müller. 2012. Addressing sustainability in the aluminum industry: a critical review of life cycle assessments. Journal of Cleaner Production 35: 108-117.

http://linkinghub.elsevier.com/retrieve/pii/S0959652612002533. Accessed December 3, 2014.

Liu, Z., Y. Geng, M. Adams, L. Dong, L. Sun, J. Zhao, H. Dong, J. Wu, and X. Tian. 2016. Uncovering driving forces on greenhouse gas emissions in China' aluminum industry from the perspective of life cycle analysis. Applied Energy. http://www.sciencedirect.com/science/article/pii/S0306261915015251.

Llorach-Massana, P., R. Farreny, and J. Oliver-Solà. 2015. Are Cradle to Cradle certified products environmentally preferable? Analysis from an LCA approach. Journal of Cleaner Production 93: 243-250. http://linkinghub.elsevier.com/retrieve/pii/S0959652615000360.

Madival, S., R. Auras, S.P. Singh, and R. Narayan. 2009. Assessment of the environmental profile of PLA, PET and PS clamshell containers using LCA methodology. Journal of Cleaner Production 17(13): 1183-1194. http://dx.doi.org/10.1016/j.jclepro.2009.03.015.

McDonough, W. and M. Braungart. 2002. Cradle to cradle. North Point Press. New York.

Moreno Ruiz, E., T. Lévová, G. Bourgault, and G. Wernet. 2014. Documentation of changes implemented in ecoinvent Data 3.1. Ecoinvent. Zurich.

Moreno Ruiz, E., T. Lévová, G. Bourgault, and G. Wernet. 2015. Documentation of changes implemented in ecoinvent database 3.2. Ecoinvent Centre. Zurich, Switzerland.

Niero, M., A.J. Negrelli, S.B. Hoffmeyer, S.I. Olsen, and M. Birkved. 2016. Closing the loop for aluminium cans: Life Cycle Assessment of progression in Cradle-to-Cradle certification levels. Journal of Cleaner Production 126: 352-362. http://dx.doi.org/10.1016/j.jclepro.2016.02.122.

Niero, M. and S.I. Olsen. 2016. Circular economy : to be or not to be in a closed product loop ? A Life Cycle Assessment of aluminium cans with inclusion of alloying elements. Resources Conservation and Recycling 114: 18-31. http://dx.doi.org/10.1016/j.resconrec.2016.06.023.

Nunez, P. and S. Jones. 2015. Cradle to gate: life cycle impact of primary aluminium production. The International Journal of Life Cycle Assessment. http://link.springer.com/10.1007/s11367015-1003-7.

PE Americas. 2010. Life Cycle Impact Assessment of Aluminum Beverage Cans. Final Report.

Pfister, S., A. Koehler, and S. Hellweg. 2009. Assessing the Environmental Impacts of Freshwater Consumption in LCA. Environmental Science \& Technology 43(11): 4098-104. http://www.ncbi.nlm.nih.gov/pubmed/19569336.

PRé. 2013. Introduction to LCA with SimaPro. PRé.

Scipioni, A., M. Niero, A. Mazzi, A. Manzardo, and S. Piubello. 2013. Significance of the use of non-renewable fossil CED as proxy indicator for screening LCA in the beverage packaging sector. International Journal of Life Cycle Assessment 18: 673-682.

Stichling, J. and D. Nguyen-Ngoc. 2009. Life Cycle Inventory and Impact Analysis for Beverage Cans. Final Report. PE International.

Sun, B., Z. Nie, F. Gao, Y. Liu, Z. Wang, and X. Gong. 2015. Cumulative exergy demand analysis of the primary aluminum produced in China and its natural resource-saving potential in transportation. The International Journal of Life Cycle Assessment: 1048-1060. http://link.springer.com/10.1007/s11367-014-0828-9.

Technical Secretariat for the Beer Pilot. 2015. Product Environmental Footprint Category Rules for 
646

647

648

649

650

651

652

653

654

655

656

657

658

659

660

661

Beer.

The University of Liverpool. 2015. Aluselect.

http://aluminium.matter.org.uk/aluselect/06_wrought_comp.asp. Accessed September 15, 2015.

Toxopeus, M.E., B.L. a. de Koeijer, and a. G.G.H. Meij. 2015. Cradle to Cradle: Effective Vision vs. Efficient Practice? Procedia CIRP 29: 384-389. http://www.sciencedirect.com/science/article/pii/S2212827115001110.

Turconi, R., A. Boldrin, and T. Astrup. 2013. Life cycle assessment (LCA) of electricity generation technologies: Overview, comparability and limitations. Renewable and Sustainable Energy Reviews 28: 555-565. http://dx.doi.org/10.1016/j.rser.2013.08.013.

UK-DECC. 2014. Updated energy and emissions projections: 2014 - Publications - GOV.UK. https://www.gov.uk/government/publications/updated-energy-and-emissions-projections-2014.

Weidema, B.P., C. Bauer, R. Hischier, C. Mutel, T. Nemecek, J. Reinhard, C.O. Vadenbo, and G. Wenet. 2013. Overview and methodology. Data quality guideline for the ecoinvent database version 3. Ecoinvent Report 1(v3). Vol. 3. St. GAllen: The ecoinvent Centre. 


\section{About the authors}

663 Monia Niero is a Researcher, Stig I. Olsen and Alexis Laurent are Associate Professors. All three 664 belong to the Division for Quantitative Sustainability Assessment (QSA), Department of 665 Management Engineering, at the Technical University of Denmark (Kgs. Lyngby, Denmark). 666 667 